\title{
Children's Health and Parental Labour Supply*
}

\author{
CHIKAKO YAMAUCHI \\ National Graduate Institute for Policy Studies, Tokyo, Japan \\ and Australian National University, ACT, Australia
}

\begin{abstract}
This paper investigates the relationship between children's long-term health problems and parental labour supply using the 2004, 2006 and 2008 Longitudinal Study of Australian Children (LSAC). The results from the individual Fixed Effects Model indicate that mothers of children aged 0 years in 2004 reduce their labour supply when their children start to show long-term health problems, and their household income declines by 8 per cent, mainly due to the partners' shift from permanent to fixed-term work. Parents of children aged 4 years in 2004 show no change in these outcomes associated with the onset of their children's longterm health problems.
\end{abstract}

\section{Introduction}

Children's health problems are likely to increase parental care responsibilities that can limit their labour supply. This poses a possible loss by parents of the financial and psychological benefits of paid employment, and previous studies suggest there is a particular need to study carers of children with disabilities. Cummins et al. (2007) showed that carers were more likely to indicate a lower level of life satisfaction compared to the general population; in particular, carers looking after children reported significantly lower levels of wellbeing compared to those looking after a spouse or other adult. ${ }^{1}$ Carers of children who face the risk of limited participation are not a negligible proportion of the population. According to the Survey of Disability, Ageing and Carers (SDAC) (Australian

* I am grateful to the editor, Paul Miller, and two anonymous referees for helpful suggestions. Staff at the Commonwealth Department of Families, Housing, Community Services and Indigenous Affairs (FaHCSIA) also provided useful comments on the earlier versions of this paper. I acknowledge support from the Social Policy Evaluation, Analysis and Research Centre at the Australian National University in preparing the earlier drafts. This paper uses unit record data from the Longitudinal Study of Australian Children (LSAC) Survey. The LSAC Project was initiated and is funded by the Australian Government Department of FaHCSIA and is managed by the Australian Institute of Family Studies (AIFS). The findings and views reported in this paper, however, are those of the author and should not be attributed to either FaHCSIA or AIFS.

JEL classifications: I1, J22, J14

Correspondence: Chikako Yamauchi, National Graduate Institute for Policy Studies, 7-22-1 Roppongi, Minato-ku, Tokyo 106-8677, Japan. Email: c-yamauchi@grips.ac.jp

${ }^{1}$ This study used the Personal Wellbeing Index, which summarises the level of satisfaction across seven aspects of personal life, such as health, living standard, safety and achieving in life. As the response rate was 37.6 per cent, the results might reflect carers who were more likely to have time to reply to the questionnaire. Furthermore, if the sample frame was based on carers registered with Carers Australia, a collaborating organisation, the survey might have excluded unregistered carers. 
Bureau of Statistics, 2003), 53,000 children aged from 0 to 4 years ( 4 per cent of the total), and 266,000 children aged from 5 to 14 years (10 per cent), had disabilities or activity limitations during 2003. ${ }^{2}$ There were 57,800 primary carers who were parents caring for their children with a disability (Commonwealth of Australia, 2007b).

Although available Australian evidence reviewed in the next section indicates lower levels of socioeconomic status and labour force attachment among parents caring for children with disabilities, evidence is relatively scarce on the longitudinal relationship between parental labour supply and their children's long-term health problems. This scarcity of evidence has limited the knowledge related to the impact of children's disability on parental labour supply, income and mental health. By filling this gap, this study advances the literature on children's health and parental outcomes for Australia. More specifically, this paper draws on a new, nationally representative dataset of children, the Longitudinal Study of Australian Children (LSAC) 2004, 2006 and 2008. It utilises the Fixed Effects Model, which improves on models for crosssectional analysis. In addition, it provides new evidence on the impact on other relevant outcomes, such as income, the receipt of governmental assistance and mental health.

The results indicate that mothers with children aged 0 years in 2004 are 8 percentage points (13 per cent of the average employment rate) more likely to cease working when their children begin to indicate a long-term health problem which has lasted, or is likely to last, for 6 months or more. In particular, mothers who have casual or part-time employment are more likely to stop working. While mothers' income does not change in association with the onset of children's long-term health problem, evidence is found for a significant decline in household income of approximately 8 per cent. The results suggest that this decline occurs because the mothers' partners shift employment status from permanent to fixed-term work. Nevertheless, parental mental health is not significantly altered when a child starts to show a long-term health problem. The remainder of this paper is organised

\footnotetext{
${ }^{2}$ See the Data Appendix for details on the SDAC definitions of a person with a disability, a profound disability, severe disability and a carer.
}

as follows. The next section reviews the previous studies and is followed by a description of the methodology used. Sections IV and V discuss data and the empirical results, respectively. The final section provides concluding remarks.

\section{Review of the Literature on Children's Health and Parental Labour Supply}

What kinds of health problems are prevalent among children in Australia? The 2003 SDAC indicates that the impairment of intellectual/ learning functions and limitations in physical activities each affect 4 per cent of children aged $0-14$ years. These are followed by sensory/ speech disabilities and psychiatric disabilities, which affect 3 per cent and 2 per cent of those children, respectively. Among children aged 0-14 years with severe or profound core activity limitations, high prevalence rates were found for asthma, speech difficulties, other mental/ behavioural disorders and ADHD. The majority of these children (more than 90 per cent) received intensive care from the mother. Close to 60 per cent of the primary carers of these children spent 40 hours or more per week engaging in care activities, while the others either reported fewer hours or did not answer the question (Australian Institute of Health and Welfare, 2006).

Given the heavy caring duties, it is not surprising that primary carers were less likely to participate in the labour force, and they indicated the lack of alternative care arrangements and difficulty in arranging working hours as a barrier to workforce participation (Commonwealth of Australia, 2007a). The simulation study conducted by the National Centre for Social and Economic Modelling (NATSEM) $(2008)^{3}$ suggests that carers' limited engagement in paid work lowers their lifetime earnings to a quarter to a half of the income of a non-carer, and at the age of 65 years, their superannuation is likely to be negligible for many carers.

A large number of international studies, based mainly on US data, also found a negative relationship between children's health and parental (particularly maternal) labour supply. Initially, the negative association between children's

\footnotetext{
${ }^{3}$ This study used the 2003 SDAC and the 2006 Household, Income and Labour Dynamics in Australia (HILDAq) Survey to study a case for women aged 30 years with two or more children, where one group comprised primary carers looking after their child with a disability and the other was composed of non-carers.
} 
health problems and maternal employment was found only for married mothers (Breslau et al., 1982; Salkever, 1982a,b; Kimmel, 1998), and the results for single mothers were initially mixed. ${ }^{4}$ However, when disabilities with differential severity are carefully distinguished (Brady et al., 1998; Lukemeyer et al., 2000; Powers, 2001, 2003), negative relationships were found between severe disability indicators and the employment of both single and married mothers.

However, children with disabilities were more likely to be found in families with a lower socioeconomic status, such as one-parent families, families with a parent with a disability and those families located in areas of greater socioeconomic disadvantage (Australian Bureau of Statistics, 2008). Therefore, it is unclear how much of the reduction in parental labour supply is due to children's health problems rather than a lower level of parental human capital or preference for paid work. In fact, using panel data, Powers (2003) demonstrated that simple crosssectional correlation may overstate the impact of a child's health problems on a married mother's work activity. She showed that growth in work hours over time, and the probabilities of entering employment, were adversely affected by a child's disability only for single, and not for married, mothers.

A number of Australian studies have also investigated how changes in employment status have been associated with changes in care responsibilities. For example, Edwards et al. (2008) provided evidence on the history of employment for a nationally representative sample of carers in receipt of carer allowance (CA) and carer payment $(\mathrm{CP}){ }^{5}$ It was found that

\footnotetext{
${ }^{4}$ No significant relationship was found between children's health and the employment status of mothers from female-headed households in some studies (Salkever, 1982a,b; Kimmel, 1997, 1998), while other studies suggested a negative relationship between children's health and maternal employment (Breslau et al., 1982; Blank, 1989; Wolfe \& Hill, 1995).

${ }^{5}$ The design of this survey, the Families Caring for a Person with Disability Study (FCPDS), meant that it excluded carers who did not receive government payments. As the two governmental payments to carers assess disability conditions of care recipients, the sample used in the FCPDS is likely to be carers of people with a relatively severe disability compared to the general population of carers in Australia. See Appendix IV for details of $\mathrm{CP}$ and $\mathrm{CA}$.
}

approximately half of carers were employed prior to the commencement of caring. Of female carers who had been employed prior to commencing caring but were not employed at the time of the interview, approximately 80 per cent answered that providing care was the main reason for leaving their job. Bittman et al. (2007) used the 2001-2004 HILDA Survey and showed that working-aged individuals who began caring between 2001 and 2004 reduced their labour supply more than those who never became carers. Similarly, those who finished caring appeared slightly more likely to increase their hours of work. The absence of statistical tests, however, has made it unclear whether these outcomes were significantly different. ${ }^{6}$

Lee and Gramotnev (2007) provided evidence that suggests that individuals who become carers have a lower level of labour force attachment. Utilising the Australian Longitudinal Study on Women's Health (ALSWH), they demonstrated that middle-aged women, who were currently, had been or were to become family caregivers over a 3-year survey period, were in poorer health than women who did not have these roles at any point in time. Poor health and disengagement from the paid workforce also continued even when care-giving stopped. They concluded that middle-aged women in poor health tended to be selected into care-giving, probably because they were less engaged with the paid workforce. These results imply that the effect of caring responsibility on labour force participation is smaller than suggested by cross-sectional data. Leigh (2007) also drew a similar conclusion. Using the 2001-2005 HILDA Survey, he showed that while there are significant crosssectional differences in labour market outcomes and life satisfaction between individuals who provided and did not provide informal care to the elderly and persons with a disability, the results based on an individual Fixed Effects model indicated that neither of the outcomes significantly alters as care arrangements change.

These studies suggest that the effect of caring responsibilities on labour force participation is

\footnotetext{
${ }^{6}$ While a negative association was found between caring and employment in a regression which pooled observations from multiple years, without controlling for individual level fixed effects, it is unclear whether this indicated the effect of caring on employment, or the tendency for individuals with lower workforce attachment to become carers.
} 
smaller than indicated by cross-sectional studies. They do not, however, distinguish carers who look after children from carers who take care of the elderly or other adults with a disability. Therefore, it is unclear whether the same findings hold for parent carers. This paper fills this gap by providing a new set of results from the 2004, 2006 and 2008 LSAC.

\section{Methodology}

The conceptual framework for the analysis is based on a simple household production function model (Becker, 1965). The model postulates that parents derive utility from a set of 'commodities' which include their child's health. To 'produce' (or improve) the child's health, parents invest their own time and market goods. The child's health can also depend on unobserved family endowments and time-variant shocks. For this paper, it is assumed that parents either work or take care of the child, and also that the child can be looked after by the parents or other carers (including formal and informal carers). Under these assumptions, parental labour supply is jointly determined with the amount of parental care time, others' care time and market goods. The optimal levels of these inputs are determined by maximising parental utility under a full income constraint.

At the optimal levels of inputs, the ratio between the marginal productivity of parental care time and that of others' care time equals the ratio of the wage rate and the hourly fee of the other carers. It is plausible to assume that the marginal productivity of parental care increases relative to that of other carers when the child's health declines due to a time-variant shock. For example, as discussed in Section II, market childcare facilities are not always available to children who have long-term health problems. Even when such facilities are available, institutional arrangements mean that carers' attention is shared with other children. The shift in the relative marginal productivity is likely to induce parents to invest more of their time in taking care of their children, thereby reducing labour supply. This paper examines whether this hypothesis is empirically supported.

More specifically, we first assess whether the labour supplied by parents whose children have health problems is different from labour supplied by other parents by pooling data from the 3 years and using the following specification:

$$
Y_{i t}=\beta_{0}+\beta_{1} H_{i t}+\beta_{2} X_{i}^{1}+\beta_{3} X_{i t}^{2}+e_{i t},
$$

where $Y_{i t}$ is the dependent variable for household $i$ at time $t, H_{i t}$ is the health status of the child surveyed in the LSAC, $X_{i t}^{1}$ is a set of timeinvariant characteristics of the mother, child and household, and $X_{i t}^{2}$ is a set of their time-variant characteristics. $^{7}$ The error term, $e_{i t}$, captures time-invariant unobserved heterogeneity across parents/families, such as parental preferences for work and care, and parents' genetic traits, as well as time-variant unobserved heterogeneity, such as accidents and illness affecting the child/parents and economic conditions altering parental employment opportunities in some of the analysis years. The error term is assumed to be independent across mothers/households, and hence clustered at the mother/household level. When a dependent variable is a dummy variable, Probit and Logit models are applied; when it is a censored variable, a Tobit model is applied. To see whether consistent results are obtained after relaxing the functional assumptions on the error term under these models (Wooldridge,

\footnotetext{
${ }^{7} X_{i t}^{1}$ includes three dummy variables indicating mothers born outside of Australia, mothers who do not speak English at home, and mothers who are Aboriginal or Torres Strait Islander. $X_{i t}^{2}$ includes mother's age, mother's age squared, and five dummy variables indicating mothers' educational attainment (differentiating mothers who completed Year 12, mothers who did not complete Year 12 but have a trade/other qualification, mothers who completed Year 12 and have a trade/other qualification, mothers who completed a Bachelor's degree, mothers who completed a graduate diploma or postgraduate degree), two dummy variables indicating mother's health status (differentiating those who reported a long-term physical health problem and those who reported a long-term mental health problem), three dummy variables indicating shocks (differentiating mothers who suffered a serious illness, injury or assault in the last year, mothers whose relatives suffered a serious illness, injury or assault in the last year, and mothers whose parent, partner, child, close family friend or another relative died), two dummy variables indicating mothers whose partners live in the household and mothers who are married to the partners, the number of the child's siblings, the number of household members other than sibling or parent, a dummy variable indicating children whose sibling is a step-, half-, adopted or foster child, and two dummy variables indicating observations in 2006 and observations in 2008 .
} 
2002, pp. 453-482), the ordinary least squares (OLS) model is also used.

The OLS results can still provide biased estimates if there are omitted variables correlated with $X_{i t}^{1}$ or $X_{i t}^{2}{ }^{8}$

One way to purge a possible omitted variable bias is to use the mother-level Fixed Effects model as follows: ${ }^{9}$

$$
Y_{i t}=\beta_{0}+\beta_{1} H_{i t}+\beta_{2} X_{i}^{1}+\beta_{3} X_{i t}^{2}+\mu_{i}+e_{i j},
$$

where $\mu_{j}$ is the fixed effects for each mother/household/child, and the new error term, $e_{i t}^{2}$, stands for only unobserved time-variant factors. This second method improves on the first because it provides estimates that take into account unobserved time-invariant heterogeneity. While a possibility of a bias due to omitted time-variant variables remains, results based on Equation (2) are more reliable than those based on Equation (1). Intuitively, it is analysed whether parents whose children changed their health status between 2004 and 2006 or 2006 and 2008, changed their labour supply behaviour compared to other parents. The clustering assumption at the mother level is kept in the Fixed Effects model analysis.

\section{Data}

The data are available for the two cohorts of children aged $0-1$ years ( $\mathrm{B}$ or Babies cohort) and from 4 to 5 years ( $\mathrm{K}$ or Kids cohort) in 2004, and who were again interviewed in the 2006 and 2008 LSAC. These three waves of LSAC contain a nationally representative sample of approximately 4500 children in each cohort. Altogether, the sample, with no missing values in necessary variables, consists of 9262 mothers

\footnotetext{
${ }^{8}$ For example, if mothers with a lower (or higher) preference for work had health problems that were not captured by the measures of maternal long-term health problems, and such unobserved ailments were genetically shared with the child, then unobserved maternal preference would cause negative (positive) spurious correlation between their labour supply and the children's long-term health problems. Also, it is known that individuals with low-income households are less likely to report health conditions when they actually have conditions (Johnston et al., 2007). Similar reporting differences might exist between individuals with different preferences for work.

${ }^{9}$ More specifically, the Fixed Effects estimates are computed using the within-transformation (Wooldridge, 2002, p. 267).
}

(households). The remainder of this section discusses the summary statistics for the two cohorts. Later, the regression analysis focuses on the results for the $\mathrm{B}$ cohort because the results for the two cohorts are significantly different and those for the $\mathrm{K}$ cohort indicate no significant change in parental labour supply or income associated with changes in children's health.

The summary statistics of the outcome variables are shown in Panel A, Table 1 (see Appendix III for detailed definitions). The level of labour supply was relatively low among the sample of mothers, with an average of 63 per cent of mothers in the sample working: in salaried work (48 per cent), in their own business or farm (14 per cent), or helping out with the family business without receiving pay. Employment outcomes like these are used as dependent variables to test whether particular types of employment are more compatible with care duties. The same set of labour market outcomes is depicted for mothers' partners in Panel E. Average maternal weekly income (including non-labour income and government payments) was $\$ 489$ (in terms of 2006 prices). Total household (or parental) income, which is defined to be the sum of maternal income and her partner's income, was $\$ 1549$ on average. ${ }^{10}$ Approximately 3 per cent of the households received the CA: an income supplement available to people who provide daily care and attention at home to a person with a disability or severe medical condition. Parental mental health is measured by the Kessler 6 indicator (Kessler et al., 2002). This indicator is based on six questions about individuals' psychological conditions in the past 4 weeks.

The explanatory variable of interest is the dummy variable indicating whether a child has a long-term physical or mental health problem (Panel B, Table 1). This is based on the questions about whether a child had any medical conditions or disabilities that lasted, or were likely to last, for 6 months or more at the time of the interview. Mental and physical health problems are combined in this study because mental health problems were almost non-existent among children. This variable is likely to be comparable to the indicators for children's disability which have been used in previous studies.

\footnotetext{
${ }^{10}$ The sum of income earned by parents was used as a proxy for household income due to data limitations. See Appendix II for details.
} 
TABle 1

Summary Statistics

\begin{tabular}{|c|c|c|c|c|c|c|}
\hline \multirow[b]{2}{*}{ Variable } & \multicolumn{2}{|c|}{ All } & \multicolumn{2}{|c|}{ Babies cohort } & \multicolumn{2}{|c|}{ Kids cohort } \\
\hline & Mean & SD & Mean & SD & Mean & SD \\
\hline \multicolumn{7}{|l|}{ A. Outcome variables } \\
\hline 1 if mother works & 0.63 & 0.48 & 0.59 & 0.49 & 0.68 & 0.47 \\
\hline $\begin{array}{l}\text { Weekly work hours (including non-workers } \\
\text { as zero) }\end{array}$ & 14.98 & 16.02 & 13.22 & 15.37 & 16.80 & 16.48 \\
\hline 1 if mother works as a permanent worker & 0.34 & 0.47 & 0.33 & 0.47 & 0.36 & 0.48 \\
\hline 1 if mother works as a fixed-term worker & 0.03 & 0.16 & 0.02 & 0.15 & 0.03 & 0.18 \\
\hline 1 if mother works as a casual worker & 0.10 & 0.31 & 0.09 & 0.29 & 0.12 & 0.32 \\
\hline 1 if mother works as a wage worker & 0.48 & 0.50 & 0.45 & 0.50 & 0.51 & 0.50 \\
\hline 1 if mother works as a self-employed worker & 0.14 & 0.35 & 0.13 & 0.34 & 0.15 & 0.36 \\
\hline $\begin{array}{l}1 \text { if mother works as a full-time worker } \\
\text { (more than } 34 \mathrm{~h} \text { per week) }\end{array}$ & 0.16 & 0.37 & 0.14 & 0.35 & 0.19 & 0.39 \\
\hline $\begin{array}{l}1 \text { if mother works as a part-time worker } \\
\text { (less than } 35 \mathrm{~h} \text { per week) }\end{array}$ & 0.47 & 0.50 & 0.45 & 0.50 & 0.50 & 0.50 \\
\hline Weekly maternal income $(\$ 1000,2006$ prices $)$ & 0.49 & 0.50 & 0.45 & 0.49 & 0.53 & 0.50 \\
\hline Weekly parental (household) income & 1.55 & 1.15 & 1.53 & 1.18 & 1.56 & 1.12 \\
\hline 1 if household receives carer allowance & 0.03 & 0.18 & 0.03 & 0.16 & 0.04 & 0.20 \\
\hline Mother's Kessler 6 mental health score & 4.43 & 0.58 & 4.46 & 0.56 & 4.40 & 0.60 \\
\hline \multicolumn{7}{|l|}{ B. Child's characteristic } \\
\hline $\begin{array}{l}1 \text { if the child reported to have long-term } \\
\text { physical or mental health problem }\end{array}$ & 0.11 & 0.31 & 0.07 & 0.26 & 0.14 & 0.35 \\
\hline \multicolumn{7}{|l|}{ C. Mother's characteristics } \\
\hline Mother's age & 35.13 & 5.67 & 33.39 & 5.46 & 36.91 & 5.33 \\
\hline Mother's age squared & 1266 & 398 & 1145 & 362 & 1391 & 394 \\
\hline 1 if mother was born outside of Australia & 0.22 & 0.41 & 0.20 & 0.40 & 0.23 & 0.42 \\
\hline 1 if mother does not speak English at home & 0.13 & 0.33 & 0.12 & 0.32 & 0.13 & 0.34 \\
\hline 1 if mother is Aboriginal or Torres & 0.02 & 0.14 & 0.02 & 0.14 & 0.02 & 0.14 \\
\hline \multicolumn{7}{|l|}{ Strait Islander } \\
\hline 1 if mother completed Year 12 & 0.14 & 0.34 & 0.14 & 0.35 & 0.13 & 0.34 \\
\hline $\begin{array}{l}1 \text { if mother did not complete Year } 12 \text { but } \\
\text { has a trade/other qualification }\end{array}$ & 0.16 & 0.37 & 0.15 & 0.36 & 0.18 & 0.39 \\
\hline $\begin{array}{l}1 \text { if mother completed Year } 12 \text { and has a } \\
\text { trade/other qualification }\end{array}$ & 0.21 & 0.41 & 0.22 & 0.42 & 0.20 & 0.40 \\
\hline 1 if mother completed Bachelor's Degree & 0.20 & 0.40 & 0.22 & 0.41 & 0.17 & 0.38 \\
\hline $\begin{array}{l}1 \text { if mother completed a graduate } \\
\text { diploma or postgraduate degree }\end{array}$ & 0.15 & 0.35 & 0.15 & 0.36 & 0.14 & 0.35 \\
\hline $\begin{array}{l}1 \text { if mother reported a long-term } \\
\text { physical health problem }\end{array}$ & 0.14 & 0.35 & 0.13 & 0.33 & 0.15 & 0.36 \\
\hline $\begin{array}{l}1 \text { if mother reported a long-term } \\
\text { mental health problem }\end{array}$ & 0.03 & 0.16 & 0.02 & 0.16 & 0.03 & 0.16 \\
\hline $\begin{array}{l}1 \text { if mother suffered a serious illness, } \\
\text { injury or assault in the last year }\end{array}$ & 0.07 & 0.25 & 0.06 & 0.24 & 0.07 & 0.26 \\
\hline $\begin{array}{l}1 \text { if mother's relatives suffered a serious } \\
\text { illness, injury or assault in the last year }\end{array}$ & 0.15 & 0.36 & 0.14 & 0.35 & 0.16 & 0.37 \\
\hline $\begin{array}{l}1 \text { if mother's parent, partner, child, close } \\
\text { family friend or another relative died }\end{array}$ & 0.24 & 0.43 & 0.23 & 0.42 & 0.24 & 0.43 \\
\hline \multicolumn{7}{|l|}{ D. Household characteristics } \\
\hline 1 if partner is in household & 0.90 & 0.31 & 0.91 & 0.28 & 0.88 & 0.33 \\
\hline 1 if mother is married to the partner & 0.78 & 0.41 & 0.77 & 0.42 & 0.79 & 0.41 \\
\hline Number of siblings & 1.36 & 1.02 & 1.20 & 1.03 & 1.53 & 0.99 \\
\hline
\end{tabular}


TABLE 1

(Continued)

\begin{tabular}{|c|c|c|c|c|c|c|c|c|c|}
\hline \multirow[b]{2}{*}{ Variable } & \multicolumn{3}{|c|}{ All } & \multicolumn{3}{|c|}{ Babies cohort } & \multicolumn{3}{|c|}{ Kids cohort } \\
\hline & \multicolumn{2}{|c|}{ Mean } & $\mathrm{SD}$ & \multicolumn{2}{|c|}{ Mean } & SD & \multicolumn{2}{|c|}{ Mean } & SD \\
\hline $\begin{array}{l}\text { Number of household members } \\
\text { other than sibling or parent }\end{array}$ & \multicolumn{2}{|c|}{0.12} & 0.52 & \multicolumn{2}{|c|}{0.14} & 0.57 & \multicolumn{2}{|c|}{0.10} & 0.45 \\
\hline $\begin{array}{l}1 \text { if one of the siblings is a step-, } \\
\text { half-, adopted or foster child }\end{array}$ & \multicolumn{2}{|c|}{0.09} & 0.29 & \multicolumn{2}{|c|}{0.08} & 0.28 & \multicolumn{2}{|c|}{0.10} & 0.30 \\
\hline 1 if observed in the second wave & \multicolumn{2}{|c|}{0.30} & 0.46 & \multicolumn{2}{|c|}{0.30} & 0.46 & \multicolumn{2}{|c|}{0.30} & 0.46 \\
\hline 1 if observed in the third wave & \multicolumn{2}{|c|}{0.32} & 0.47 & \multicolumn{2}{|c|}{0.32} & 0.47 & \multirow{2}{*}{\multicolumn{2}{|c|}{0.32}} & 0.47 \\
\hline 1 if belongs to the Kids cohort & 0.4 & & 0.50 & & & & & & \\
\hline Number of observations (mother $*$ year) & \multicolumn{3}{|c|}{22,457} & \multicolumn{3}{|c|}{11,400} & \multicolumn{3}{|c|}{11,057} \\
\hline $\begin{array}{l}\text { Number of observations with no missing } \\
\text { values for maternal income }\end{array}$ & \multicolumn{3}{|c|}{21,241} & \multicolumn{3}{|c|}{10,821} & \multicolumn{3}{|c|}{10,420} \\
\hline $\begin{array}{l}\text { Number of observations with no missing } \\
\text { values for parental income }\end{array}$ & \multicolumn{3}{|c|}{21,674} & \multicolumn{3}{|c|}{11,059} & \multicolumn{3}{|c|}{10,615} \\
\hline $\begin{array}{l}\text { Number of observations with no missing } \\
\text { values for mother's K6 score }\end{array}$ & \multicolumn{3}{|c|}{22,331} & \multicolumn{3}{|c|}{11,348} & \multicolumn{3}{|c|}{10,983} \\
\hline Unique number of observations (mother) & \multicolumn{3}{|c|}{9262} & & 4696 & & & 456 & \\
\hline & & All & & $\mathrm{Bal}$ & ies coho & & & ds $\operatorname{coh}$ & \\
\hline Variable & $N$ & Mean & SD & $N$ & Mean & SD & $N$ & Mean & SD \\
\hline E. Characteristics of mothers' partners & & & & & & & & & \\
\hline 1 if mother's partner works & 20,094 & 0.95 & 0.21 & 10,394 & 0.95 & 0.22 & 9700 & 0.95 & 0.21 \\
\hline $\begin{array}{l}\text { Weekly work hours of partner (including } \\
\text { non-workers as zero) }\end{array}$ & 20,062 & 44.71 & 16.17 & 10,367 & 44.42 & 15.94 & 9695 & 45.02 & 16.40 \\
\hline $\begin{array}{l}1 \text { if mother's partner works as a } \\
\text { permanent worker }\end{array}$ & 20,094 & 0.64 & 0.48 & 10,394 & 0.65 & 0.48 & 9700 & 0.63 & 0.48 \\
\hline $\begin{array}{l}1 \text { if mother's partner works as a } \\
\text { fixed-term worker }\end{array}$ & 20,094 & 0.02 & 0.15 & 10,394 & 0.03 & 0.16 & 9700 & 0.02 & 0.15 \\
\hline $\begin{array}{l}1 \text { if mother's partner works as a } \\
\text { casual worker }\end{array}$ & 20,094 & 0.04 & 0.18 & 10,394 & 0.04 & 0.19 & 9700 & 0.03 & 0.18 \\
\hline $\begin{array}{l}1 \text { if mother's partner works as a } \\
\text { wage worker }\end{array}$ & 20,094 & 0.70 & 0.46 & 10,394 & 0.71 & 0.45 & 9700 & 0.68 & 0.47 \\
\hline $\begin{array}{l}1 \text { if mother's partner works as a } \\
\text { self-employed worker }\end{array}$ & 20,094 & 0.25 & 0.43 & 10,394 & 0.23 & 0.42 & 9700 & 0.27 & 0.44 \\
\hline $\begin{array}{l}1 \text { if mother's partner works as a } \\
\text { full-time worker } \\
\text { (more than } 34 \mathrm{~h} \text { per week) }\end{array}$ & 20,122 & 0.89 & 0.31 & 10,408 & 0.88 & 0.32 & 9714 & 0.89 & 0.31 \\
\hline $\begin{array}{l}1 \text { if mother's partner works as a } \\
\text { part-time worker } \\
\text { (less than } 35 \mathrm{~h} \text { per week) }\end{array}$ & 20,122 & 0.61 & 0.49 & 10,408 & 0.61 & 0.49 & 9714 & 0.61 & 0.49 \\
\hline Partner's Kessler 6 mental health score & 17,621 & 4.47 & 0.54 & 9089 & 4.48 & 0.54 & 8532 & 4.47 & 0.55 \\
\hline
\end{tabular}

Note: See Appendix III for the definition of the variables and the description of the sample.

Sources: The 2004, 2006 and 2008 Longitudinal Study of Australian Children (B and K Cohorts).

In estimating the likelihood of employment and income, the following regression analysis controls for the basic demographic characteristics (such as age, migration, marital and Indigenous status, as well as the language spoken at home) and human capital (measured by educational and skills attainment, as well as long-term health problems) of mothers (Panel C, Table 1). Also controlled are the household characteristics, such as marital status, the number of siblings and household members other than the child or parents (Panel D). 


\section{$V$ Results}

For simplicity, only the coefficient for the indicator for children's long-term health status is shown in all the regression results. They are estimated while simultaneously controlling for the conventional covariates listed in Panels B-D in Table 1. As an example, the full results of the regression of the dummy variable for maternal labour force participation on those covariates are indicated in Columns 1-3, Appendix II.

\section{(i) Parental Labour Supply}

The regression results for parental labour supply are shown in Table 2. The first three columns in Panel A indicate the estimates for the association between maternal work and the child's longterm health problem based on the Probit, Logit and linear probability models, which are substantively consistent. The results imply that the probability of being at work is 8 percentage points lower among mothers living with a child with a long-term health problem. The results in Columns 4-5 also indicate that the number of work hours is $1.5-3.6 \mathrm{~h}$ less for mothers whose children have long-term health problems.

As discussed in Section III, the results of the fixed effects model estimation, shown in Columns 6 and 7, are more likely to shed light on the causal effect of children's health problems on maternal employment as this type of estimation can control for unobserved factors as long as these do not change over time. These fixed effects results show that as a child developed health problems between the LSAC waves, the mother became 7.8 percentage points less likely to be working and the average weekly work hours declined by $1 \mathrm{~h}$. These results suggest that the estimates in the cross-sectional analysis are not largely overestimated. ${ }^{11}$ Nevertheless, the exercise conducted for the $\mathrm{K}$ cohort (results are not shown) indicates no longitudinal relationship between maternal labour supply and the child's long-term health problems even though it shows a significant cross-sectional relationship. Therefore, the issue of endogeneity appears to be more severe for mothers with older children aged 4-8 years. This finding for the $\mathrm{K}$ cohort is consis-

\footnotetext{
${ }^{11}$ The relationship between the dummy for maternal labour force participation and the covariates do not change after additionally including the indicator for children's health problems.
}

tent with several previous studies (Powers, 2003; Lee \& Gramotnev, 2007; Leigh, 2007).

Panel B in Table 2 depicts the same set of results for mothers' partners. There is weak evidence that partners who live with a child having a long-term health problem are less likely to be at work (Columns 1-3). However, changes in a child's long-term health problem are not significantly correlated with a change in partners' employment or work hours (Columns 6 and 7). These results seem to suggest that mothers' partners (mostly fathers of the child) do not change their labour supply behaviour at the onset of the children's long-term health problems. Nevertheless, a closer look into employment status reveals that partners became slightly more likely to be engaged in fixed-term work, rather than permanent work, when children develop long-term health problems (Panel B, Table 3). If fixed-term work provides more flexibility to take care of the children with long-term health problems, partners might have viewed it to be a more suitable option.

The results for employment status exhibit a different pattern between mothers and their partners. For mothers (Panel A, Table 3), negative effects are concentrated among casual rather than permanent, and part-time rather than full-time, work. One explanation for these results is that mothers who had been more attached to the labour force (permanent, full-time workers) were less likely to stop working at the onset of the child's long-term health problems. It might be that the opportunity costs for these mothers of quitting work were higher than the CA could compensate. These results also imply that the mothers whose children stopped exhibiting long-term health problems began to participate in the labour market as casual, rather than permanent, and as part-time, rather than full-time, workers. The results also indicate concentrated negative effects for paid and self-employment rather than unpaid work for family. This is likely to reflect that paid employment is the least compatible with care for children and it is difficult for mothers who had held those jobs to continue working when their child began to indicate long-term health problems.

\section{(ii) Household Income and Government Assistance}

One significant consequence of ceasing work is the loss of income. While there are governmental payments available for those carers whose earning opportunities are limited due to their caring responsibilities, it is unclear 
TABLE 2

Parental Labour Supply and the Children's Long-term Health Problems in Australia (2004, 2006 and 2008)

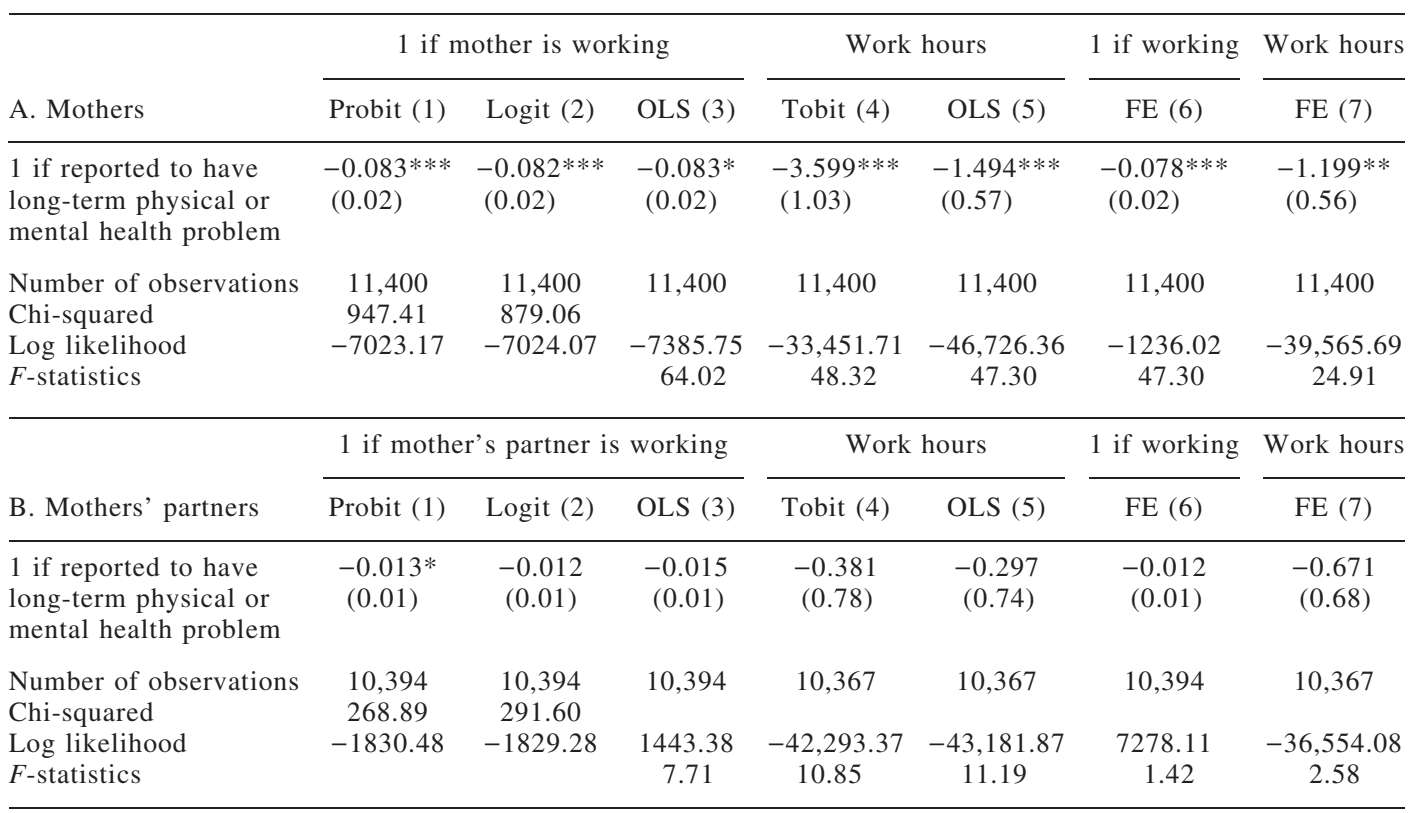

Notes: Robust standard errors in parentheses. *Significant at $10 \%$; **significant at $5 \%$; ***significant at $1 \%$.-All the regressions control mother's age, mother's age squared, the five dummy variables indicating mother's educational attainment, the two dummy variables indicating mother's health status, the three dummy variables indicating health shocks to mothers and their family/friends, the two dummy variables indicating mothers whose partners live in the household and mothers who are married to the partners, the number of the child's siblings, the number of household members other than sibling or parent, the dummy variable indicating children whose sibling is a step-, half-, adopted or foster child, and the two dummy variables indicating observations in 2006 and observations in 2008. Cross-sectional regressions additionally include the three dummy variables indicating mothers born outside of Australia, mothers who do not speak English at home, and mothers who are Aboriginal or Torres Strait Islander. See Appendix III for a more detailed definition of the variables. The number of observations differs across regressions for different outcomes due to missing values. See Appendix III for more information on the sample.

Sources: The 2004, 2006 and 2008 Longitudinal Study of Australian Children (B Cohort).

whether they are enough to compensate for the income loss. This section examines how children's health status is associated with maternal income, government payment receipt, household income and parents' mental health. The crosssectional results in Table 4 (Columns 1 and 2) suggest that a mother's income is not correlated with whether she has a child who has a longterm health problem, even though having such a child is found to be associated with maternal work in Table 2. A consistent pattern is found for the household income (Columns 4 and 5). However, the Fixed Effects results (Column 6) suggest that household income declined significantly by $\$ 124$ per week among households where a child began to report a long-term health problem. This represents 8 per cent of the average weekly household income (\$1534). Given the absence of change in maternal income (Column 3), the decline in household income is likely to be due to changes in partners' income. As their work hours are shown to be uncorrelated with their children's health changes, the shift in partners' employment status is likely to have caused the decline in household income.

One of the reasons for the absence of a significant correlation between children's long-term health problems and maternal income (Panel A, Table 4) might be because a loss due to employment termination is offset by government payments to households with children with disabilities. In Australia, the main government payments directed to carers are $\mathrm{CP}$ and $\mathrm{CA}$. CP is given to people who cannot support themselves through substantial paid employment due to caring responsibilities. It is subject to income 
TABLE 3

Parental Employment Status and the Children's Long-Term Health Problems in Australia (2004, 2006, and 2008): Fixed Effects Model

\begin{tabular}{|c|c|c|c|c|c|c|c|}
\hline \multirow[b]{2}{*}{ A. Mothers } & \multicolumn{7}{|c|}{1 if mother works as: } \\
\hline & $\begin{array}{l}\text { Permanent } \\
\text { worker (1) }\end{array}$ & $\begin{array}{c}\text { Term } \\
\text { worker }\end{array}$ & $\begin{array}{c}\text { Casual } \\
\text { worker (2) }\end{array}$ & $\begin{array}{c}\text { Wage } \\
\text { worker (3) }\end{array}$ & $\begin{array}{l}\text { Self-employed } \\
\text { worker (4) }\end{array}$ & $\begin{array}{l}\text { Full-time } \\
\text { worker (5) }\end{array}$ & $\begin{array}{l}\text { Part-time } \\
\text { worker (6) }\end{array}$ \\
\hline $\begin{array}{l}1 \text { if reported to have } \\
\text { long-term physical } \\
\text { or mental health problem }\end{array}$ & $\begin{array}{c}-0.015 \\
(0.02)\end{array}$ & $\begin{array}{r}-0.001 \\
(0.01)\end{array}$ & $\begin{array}{c}-0.028 * \\
(0.02)\end{array}$ & $\begin{array}{l}-0.051 * * * \\
(0.02)\end{array}$ & $\begin{array}{l}-0.026^{* *} \\
(0.01)\end{array}$ & $\begin{array}{c}-0.008 \\
(0.02)\end{array}$ & $\begin{array}{l}-0.070^{* * *} \\
(0.02)\end{array}$ \\
\hline $\begin{array}{l}\text { Number of observations } \\
\text { Log likelihood } \\
F \text {-statistics }\end{array}$ & $\begin{array}{c}11,400 \\
-173.11 \\
10.80\end{array}$ & $\begin{array}{c}11,400 \\
9626.95 \\
2.58\end{array}$ & $\begin{array}{c}11,400 \\
1926.89 \\
1.96\end{array}$ & $\begin{array}{c}11,400 \\
-1181.48 \\
15.63\end{array}$ & $\begin{array}{c}11,400 \\
2604.46 \\
3.85\end{array}$ & $\begin{array}{c}11,400 \\
1994.38 \\
7.50\end{array}$ & $\begin{array}{c}11,400 \\
-2447.71 \\
11.02\end{array}$ \\
\hline
\end{tabular}

1 if mother's partner works as:

\begin{tabular}{lccccccc}
\cline { 2 - 7 } B. Mothers' partners & $\begin{array}{c}\text { Permanent } \\
\text { worker (1) }\end{array}$ & $\begin{array}{c}\text { Term } \\
\text { worker }\end{array}$ & $\begin{array}{c}\text { Casual } \\
\text { worker (2) }\end{array}$ & $\begin{array}{c}\text { Wage } \\
\text { worker (3) }\end{array}$ & $\begin{array}{c}\text { Self-employed } \\
\text { worker (4) }\end{array}$ & $\begin{array}{c}\text { Full-time } \\
\text { worker (5) }\end{array}$ & $\begin{array}{c}\text { Part-time } \\
\text { worker (6) }\end{array}$ \\
\hline $\begin{array}{l}\text { 1 if reported to have } \\
\text { long-term physical }\end{array}$ & -0.017 & $0.019 * *$ & -0.010 & -0.002 & -0.009 & -0.011 & -0.007 \\
or mental health problem & $(0.02)$ & $(0.01)$ & $(0.01)$ & $(0.02)$ & $(0.01)$ & $(0.02)$ & $(0.01)$ \\
Number of observations & 10,394 & 10,394 & 10,394 & 10,394 & 10,394 & 10,408 & 10,408 \\
$\begin{array}{l}\text { Log likelihood } \\
F \text {-statistics }\end{array}$ & 611.29 & 8395.88 & 7204.86 & 1910.76 & 3142.46 & 3140.26 & 4202.45 \\
& 0.81 & 1.50 & 0.97 & 1.40 & 3.39 & 1.21 & 1517.26
\end{tabular}

Notes: Robust standard errors in parentheses. *Significant at $10 \% ; * *$ significant at $5 \%$;***ignificant at $1 \%$. All the regressions are a Fixed Effects model, and control mother's age, mother's age squared, the five dummy variables indicating mother's educational attainment, the two dummy variables indicating mother's health status, the three dummy variables indicating health shocks to mothers and their family/friends, the two dummy variables indicating mothers whose partners live in the household and mothers who are married to the partners, the number of the child's siblings, the number of household members other than sibling or parent, the dummy variable indicating children whose sibling is a step-, half-, adopted or foster child, and the two dummy variables indicating observations in 2006 and observations in 2008. The number of observations differs across regressions for different outcomes due to missing values. See Appendix III for more information on the sample.

Sources: The 2004, 2006 and 2008 Longitudinal Study of Australian Children (B Cohort).

and assets tests, hence $\mathrm{CP}$ is reduced when carers earn more than a certain amount of income and terminated when it exceeds the upper limit set under CP criteria. As at $20 \mathrm{March}$ 2008 (2008 was the final year of data used), the maximum rate was $\$ 456.80$ per fortnight for partnered carers and $\$ 546.80$ for single carers. CA is a supplementary payment to people who provide daily care in a private home to a person with a disability. Unlike CP, it is neither taxable nor income or asset tested. It can be paid additionally to a social security income support payment such as CP. As at 20 March 2008, \$100.60 was provided per fortnight (see Appendix IV for more details on $\mathrm{CA}$ and $\mathrm{CP}$ ). As the income measures include government allowances, a low level of labour earnings and business/share profits can be mitigated by such allowances (see Appendix III for details on income measures).
The results for CA receipt (Columns 1-4, Panel B, Table 4) provide an indication that this may be the case. That is, households where a child began to show a long-term health problem are 3 percentage points more likely to start receiving CA. ${ }^{12}$ This finding is unchanged when the outcome variable is more specifically defined to indicate if the mother, as opposed to anyone in the household, receives CA, because mothers are the recipients in 94 per cent of the cases. A possible explanation for these results is that government payments offset a gap in maternal income between households with and

12 The results based on cross-sectional analysis, particularly OLS, are overestimated with the point estimates indicating a 1-6 percentage points higher likelihood of starting to receive CA. 
TABLE 4

Income, Carer Payment, Parents' Mental Health and the Children's Long-term Health Problems in Australia (2004, 2006 and 2008)

\begin{tabular}{|c|c|c|c|c|c|c|}
\hline \multirow{2}{*}{$\begin{array}{l}\text { A. Maternal and } \\
\text { household income }\end{array}$} & \multicolumn{3}{|c|}{ Maternal income } & \multicolumn{3}{|c|}{ Household income } \\
\hline & Tobit (1) & OLS (2) & FE (3) & Tobit (4) & OLS (5) & FE (6) \\
\hline $\begin{array}{l}1 \text { if reported to have } \\
\text { long-term physical } \\
\text { or mental health problem }\end{array}$ & $\begin{array}{c}0.000 \\
(0.03)\end{array}$ & $\begin{array}{l}0.000 \\
(0.02)\end{array}$ & $\begin{array}{c}-0.006 \\
(0.02)\end{array}$ & $\begin{array}{c}-0.062 \\
(0.05)\end{array}$ & $\begin{array}{c}-0.058 \\
(0.04)\end{array}$ & $\begin{array}{l}-0.124 * * * \\
(0.05)\end{array}$ \\
\hline $\begin{array}{l}\text { Number of observations } \\
\text { Log likelihood } \\
F \text {-statistics }\end{array}$ & $\begin{array}{c}10,821 \\
-8163.98 \\
26.33\end{array}$ & $\begin{array}{c}10,821 \\
-7233.47 \\
42.38\end{array}$ & $\begin{array}{c}10,821 \\
228.67 \\
25.01\end{array}$ & $\begin{array}{c}11,059 \\
-16,553.91 \\
105.93\end{array}$ & $\begin{array}{c}11,059 \\
-16,490.56 \\
1102.22\end{array}$ & $\begin{array}{c}11,059 \\
-8790.67 \\
42.07\end{array}$ \\
\hline
\end{tabular}

K6 mental health score

\begin{tabular}{|c|c|c|c|c|c|c|c|c|}
\hline \multirow{3}{*}{$\begin{array}{l}\text { B. Carer payment } \\
\text { and parents' } \\
\text { mental health }\end{array}$} & \multirow{2}{*}{\multicolumn{4}{|c|}{1 if receiving carer payment }} & \multirow{2}{*}{\multicolumn{2}{|c|}{ Mother }} & & \\
\hline & & & & & & & \multicolumn{2}{|c|}{ Partner } \\
\hline & Probit (1) & Logit (2) & OLS (3) & FE (4) & OLS (5) & $\mathrm{FE}(6)$ & OLS (7) & FE (8) \\
\hline $\begin{array}{l}1 \text { if reported to have } \\
\text { long-term physical } \\
\text { or mental health } \\
\text { problem }\end{array}$ & $\begin{array}{l}0.044 * * * \\
(0.00)\end{array}$ & $\begin{array}{l}0.041 \text { *** } \\
(0.00)\end{array}$ & $\begin{array}{l}0.087 * * * \\
(0.01)\end{array}$ & $\begin{array}{l}0.026 * * * \\
(0.01)\end{array}$ & $\begin{array}{l}-0.053 * * * \\
(0.02)\end{array}$ & $\begin{array}{c}-0.022 \\
(0.02)\end{array}$ & $\begin{array}{c}-0.030 \\
(0.02)\end{array}$ & $\begin{array}{c}-0.022 \\
(0.02)\end{array}$ \\
\hline $\begin{array}{l}\text { Number of } \\
\text { observations }\end{array}$ & 11,400 & 11,400 & 11,400 & 11,400 & 11,348 & 11,348 & 9089 & 9089 \\
\hline Chi-squared & 361.50 & 346.93 & & & & & & \\
\hline Log likelihood & -1195.69 & -1202.98 & 5015.57 & $10,914.31$ & -8866.86 & -2331.71 & -7174.43 & -1470.06 \\
\hline$F$-statistics & & & 22.13 & 3.28 & 55.24 & 8.70 & 5.18 & 2.28 \\
\hline
\end{tabular}

Notes: Robust standard errors in parentheses. *Significant at $10 \%$; * significant at $5 \%$; ***significant at $1 \%$. All the regressions control mother's age, mother's age squared, the five dummy variables indicating mother's educational attainment, the two dummy variables indicating mother's health status, the three dummy variables indicating health shocks to mothers and their family/friends, the two dummy variables indicating mothers whose partners live in the household and mothers who are married to the partners, the number of the child's siblings, the number of household members other than sibling or parent, the dummy variable indicating children whose sibling is a step-, half-, adopted or foster child, and the two dummy variables indicating observations in 2006 and observations in 2008. Cross-sectional regressions additionally include the three dummy variables indicating mothers born outside of Australia, mothers who do not speak English at home, and mothers who are Aboriginal or Torres Strait Islander. See Appendix III for a more detailed definition of the variables. The number of observations differs across regressions for different outcomes due to missing values. See Appendix III for more information on the sample.

Sources: The 2004, 2006 and 2008 Longitudinal Study of Australian Children (B Cohort).

without a child who begins to indicate long-term health problems. An alternative explanation is that given the commencement of a child's health problems, only those mothers who can maintain an income level by receiving the CA stop working. In other words, mothers who would not receive enough income from other sources are likely to stay in the workforce. ${ }^{13}$

\footnotetext{
${ }^{13}$ Parents might also react to the emergence of the child's long-term health problem depending on the conditions. A recent study by Gould (2004) suggests that mothers whose child has a disability which requires expensive treatments rather than parental time tend to be in the workforce.
}

(iii) Parents' Mental Health and Heterogeneity in the Association between Children's Health Problems and Parental Outcomes

A child's long-term health problems can affect parental mental health. The onset of health problems increases care duties and parents have to juggle the caring role with the requirements of everyday living (Raina et al., 2005). Coupled with the financial costs of treatment for their children, caring duties could cause acute fatigue and stress, resulting in worsened parental mental health. The psychology and medical literatures indicate that mothers who have children with a disability (chronic palsy) exhibit lower level scores for the quality 
of life (Eker \& Tüzün, 2004), and more severe behavioural problems of a child are negatively associated with parental physical and mental health (Raina et al., 2005). In addition, parents caring for children with chronic illness (ventilator dependency and cystic fibrosis) are more likely to report shorter total sleep time and sleep disruptions due to nighttime care and stress related to their child's health (Meltzer \& Mindell, 2006). Using the first wave of LSAC, Emerson and Llewellyn (2008) show that mothers of children at risk of disability are more likely to exhibit the K6 scale indicative of mental distress. However, there is relatively scarce evidence on the longitudinal relationship between a child's health problems and parental mental health, and the available evidence indicates somewhat mixed results. ${ }^{14}$

Based on our Fixed Effects model estimation, no significant change is found in parental mental health associated with the onset of the child's long-term health problem (Columns 6 and 8, Panel B, Table 4). This contrasts with the crosssectional results, which indicate lower K6 mental health scores for mothers of children who have long-term health problems (Column 5). One might consider the possibility that the effect on parental mental health is captured in the indicator for maternal long-term psychological problems. However, removing the indicator does not alter the results qualitatively. Therefore, parental mental health is not significantly altered in association with changes in the child's long-term health, as long as measured by the K6 score.

Lastly, Table 5 shows the heterogeneity in the relationship between a child's long-term health problem and the outcomes. As the incidence of long-term health problems of children is relatively rare, the estimates are not accurately computed. Available evidence suggests that work hours were particularly reduced

\footnotetext{
${ }^{14}$ For example, Wijnberg-Williams et al. (2006) reported a higher level of psychological distress for parents of children who are diagnosed with cancer. They showed that distress dissipated to the level comparable to the norm group after 5 years. In contrast, Gowen et al. (1989) reported that mothers with children who have disabilities and mothers with healthy children did not indicate a significant difference in the level of depression while they were followed (children were aged 6-27 months), although within each group maternal depression was correlated with the difficulty of caregiving or children's irritability.
}

among mothers who were relatively educated (Column 2), and who are likely to have ceased full-time employment (Column 4). The partners' work hours are found to have increased at the onset of children's health problems, given that the household initially had other adult members (Column 7). The tendency to receive $\mathrm{CP}$ at the onset of children's health problems is mitigated if the mother was not married or had other children, as at 2004 (Column 10). Maternal mental health score exhibits a particularly negative decline associated with the emergence of children's health problems if there are psychological conditions (Column 11). ${ }^{15}$

\section{Conclusions}

This paper has investigated the cross-sectional and longitudinal relationships between parental labour supply and children's long-term health problems using the 2004-2008 LSAC. The first set of major findings is that parents of B cohort children consistently indicate the negative relationship between their labour supply and their children's long-term health problems, in both cross-sectional and longitudinal analyses. In contrast, parents of $\mathrm{K}$ cohort children do not show a significant change in their labour supply at the onset of their children's long-term health problems. This heterogeneity suggests parents of very small children (aged from 0 to 4 years) are more likely to adjust their labour supply according to their child's health status, relative to mothers of children aged 4-8 years. This might be because many mothers in the $\mathrm{B}$ cohort have not fully returned to the workforce after giving birth and their income levels were lower than the $\mathrm{K}$ cohort, which makes it easier for B cohort mothers to withdraw from the labour force. Alternatively, carer arrangements might be more available for older children. For the $\mathrm{K}$ cohort, no other significant change was found in

\footnotetext{
${ }^{15}$ The $\mathrm{B}$ and $\mathrm{K}$ cohort in the LSAC were aged 4 years in 2008 and 2004, respectively. Their data at the age of four indicate the same cross-sectional relationships between the outcomes examined in this paper and the covariates. Finally, the effect of age in months can be examined in the data pooling the $\mathrm{B}$ and $\mathrm{K}$ cohorts. The results suggest that a child's age is positively associated with maternal labour supply, maternal and parental income; and it is negatively associated with maternal mental health score (results are not shown).
} 


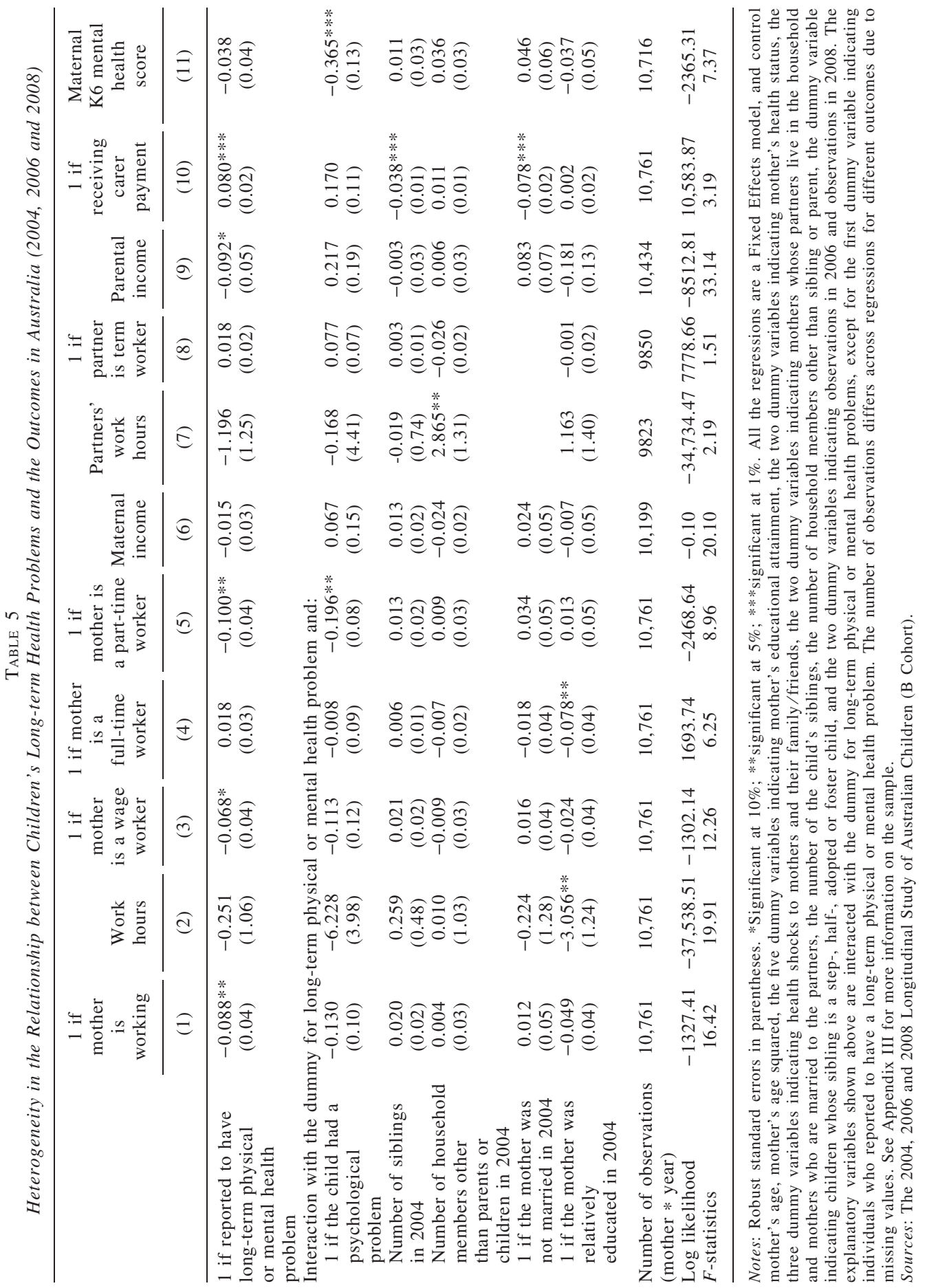


household income, governmental assistance or mental health in the longitudinal analysis.

Another set of major findings is from the longitudinal analysis for the $\mathrm{B}$ cohort. It shows that with the onset of their child's health problems, maternal labour supply decreased, the probability of receiving $\mathrm{CA}$ increased and maternal income did not change. These results might be taken to imply that a loss in maternal wage income is offset by the government payment at least partially, and mothers whose forgone wage would not have been compensated by government payments did not stop working. In contrast, household income significantly declined by approximately 8 per cent as partners became more engaged in fixed term, rather than permanent, work. The results imply that partners' shift towards more flexible jobs has resulted in a lower pay which made a difference in household income.

Finally, no change is found in parental mental health in association with the child's long-term health problems, which is not in line with the negative correlation between parental life satisfaction and their caring duties previously found in some studies. It is likely that crosssectional data provide spurious negative correlation because unobserved parental or household characteristics are correlated with both the parents' mental health and the child's long-term health problems. Therefore, the results underline the importance of utilising longitudinal information and controlling for observed as well as unobserved characteristics in assessing the relationship between disadvantages such as children's disability and parental wellbeing.

These results improve on previous studies based on cross-sectional analysis; however, there is still a possible issue of endogeneity, in particular reverse causality, even in the Fixed Effects model results. For example, factors not observed in the data might have affected parental labour supply which resulted in a decline in overall household resources and hence an emergence of the child's long-term health problems. Therefore, it would be fruitful for future research to investigate the validity of the fixed effects estimates using exogenous factors that affect only children's health status, and not the parental labour market and other outcomes.

\section{Supporting Information}

Additional supporting information may be found in the online version of this article:

Data S1 Datasets and Codes
Wiley-Blackwell is not responsible for the content or functionality of any supporting materials supplied by the authors. Any queries (other than missing material) should be directed to the corresponding author for the article.

\section{REFERENCES}

Australian Bureau of Statistics (2003), 'Disability, Ageing and Carers, Australia: Summary of Findings, 2003', 4430.0, downloaded from the website of Australian Bureau of Statistics.

Australian Bureau of Statistics (2008), 'Australian Social Trends 2008: Families with a Young Child with a Disability', 4102.0, downloaded from the website of Australian Bureau of Statistics.

Australian Institute of Health and Welfare (2006), 'Disability Update: Children with Disabilities', July.

Becker, G. (1965), 'A Theory of the Allocation of Time', Economic Journal, 75, 493-517.

Bittman, M., Hill, T. and Thomson, C. (2007), 'The Impact of Caring on Informal Carers' Employment, Income and Earnings: A Longitudinal Approach', Australian Journal of Social Issues, 42, 255-77.

Blank, R. (1989), 'The Effect of Medical Need and Medicaid on AFDC Participation', Journal of Human Resources, 24, 54-87.

Brady, H., Meyers, M. and Luks, S. (1998), 'The Impact of Child and Adult Disabilities on the Duration of Welfare Spells', UC Data-University of California Working Paper 12.

Breslau, N., Salkever, D. and Staruch, K. (1982), 'Women's Labor Force Activity and Responsibilities for Disabled Dependents: A Study of Families with Disabled Children', Journal of Health and Social Behavior, 23, 169-83.

Commonwealth of Australia (2007a), Carer Payment (child): A New Approach, Report of Carer Payment (child) Review Taskforce, Department of Family, Housing. Community Services and Indigenous Affairs, Canberra.

Commonwealth of Australia (2007b), Carer Payment (child): Statistical Compendium. Department of Family, Housing, Community Services and Indigenous Affairs, Canberra.

Cummins, R., Hughes, J., Tomyn, A., Gibson, A., Woerner, J. and Lai, L. (2007), The Wellbeing of Australians: Carer Health and Wellbeing. Australian Unity Wellbeing Index Survey 17.1.

Edwards, B., Higgins, D., Gray, M., Zmijewski, N. and Kingston, M. (2008), 'The Nature and Impact of Caring for a Family Member with a Disability in Australia', Australian Institute of Family Studies Research Report 16.

Eker, L. and Tüzün, E.H. (2004), 'An Evaluation of Quality of Life of Mothers of Children with Cerebral Palsy', Disability and Rehabilitation, 26, 1354-9.

Emerson, E. and Llewellyn, G. (2008), 'The Mental Health of Australian Mothers and Fathers of Young 
Children at Risk of Disability', Australian and New Zealand Journal of Public Health, 32, 53-9.

Gould, E. (2004), 'Decomposing the Effect of Children's Health on Mother's Labor Supply: Is It Time or Money?'Health Economics, 13, 525-41.

Gowen, J.W., Johnson-Martin, N., Goldman, B.D. and Appelbaum, M. (1989), 'Feelings of Depression and Parenting Competence of Mothers of Handicapped and Nonhandicapped Infants: A Longitudinal Study', American Journal on Mental Retardation, 94, 259-71.

Johnston, D.W., Propper, C. and Shields, M.A.. (2007), 'Comparing Subjective and Objective Measures of Health: Evidence from Hypertension for the Income/Health Gradient', IZA Discussion Paper 2737.

Kessler, R.C., Andrews, G., Colpe, L.J., Hiripi, E., Mroczek, D.K., Normand, S.-L.T., Walters, E.E. and Zaslavsky, A. (2002), 'Short Screening Scales to Monitor Population Prevalences and Trends in Nonspecific Psychological Distress', Psychological Medicine, 32, 959-76.

Kimmel, J. (1997), 'Reducing the Welfare Dependence of Unmarried Mothers: Health-Related Employment Barriers and Policy Responses', Eastern Economic Journal, 23, 151-63.

Kimmel, J. (1998), 'Child Care Costs as a Barrier to Employment for Single and Married Mothers', Review of Economics and Statistics, 80, 287-99.

Lee, C. and Gramotnev, H. (2007), 'Transitions into and out of Care-giving: Health and Social Characteristics of Mid-age Australian Women', Psychology and Health, 22, 193-209.

Leigh, A. (2007), 'Informal Care and Labour Market Participation', Labour Economics, 17, 140-9.

Lukemeyer, A., Meyers, M. and Smeeding, T. (2000), 'Expensive Children in Poor Families: Out-ofpocket Expenditures for the Care of Disabled and Chronically Ill Children in Welfare Families', Journal of Marriage and the Family, 62, 399-415.
Meltzer, L.J. and Mindell, J.A. (2006), 'Impact of a Child's Chronic Illness on Maternal Sleep and Daytime Functioning', Archives of Internal Medicine, 166, 1749-55.

National Centre for Social and Economic Modelling (NATSEM) (2008), Women Carers in Financial Stress Report. University of Canberra, Canberra.

Powers, E. (2001), 'New Estimates of the Impact of Child Disability on Maternal Employment', American Economic Review Papers and Proceedings, 91, 135-9.

Powers, E. (2003), 'Children's Health and Maternal Work Activity: Estimates under Alternative Disability Definitions', Journal of Human Resources, 38, 522-56.

Raina, P., O’Donnell, M., Rosenbaum, P., Brehaut, J., Walter, S.D., Russell, D., Swinton, M., Zhu, B. and Wood, E. (2005), 'The Health and Well-Being of Caregivers of Children with Cerebral Palsy', Pediatrics, 115, e626-36.

Salkever, D. (1982a), 'Children's Health Problems and Maternal Work Status', Journal of Human Resources, 17, 94-109.

Salkever, D. (1982b), 'Children's Health Problems: Implications for Parental Labor Supply and Earnings', in Fuchs, V. (ed.), Economic Aspects of Health. University of Chicago Press, Chicago; 22152

Wijnberg-Williams, B.J., Kamps, W.A., Klip, E.C. and Hoekstra-Weebers, J.E.H.M. (2006), 'Psychological Adjustment of Parents of Pediatric Cancer Patients Revisited: Five Years Later', PsychoOncology, 15, 1-8.

Wolfe, B. and Hill, S. (1995), 'The Effect of Health on the Work Effort of Single Mothers', Journal of Human Resources, 30, 42-62.

Wooldridge, J.M. (2002), Econometric Analysis of Cross Section and Panel Data. MIT Press, Cambridge, MA. 


\section{Appendix I}

Definitions used in the Survey of Disability, Ageing and Carers (SDAC)

The Survey defined a person as having a disability if the person reported having a limitation or impairment which lasted, or was likely to last, for at least six months and restricted everyday activities. This is in line with the International Classification of Functioning, Disability and Health's (ICF) definition of disability as an umbrella term for impairments, activity limitations and participation restrictions. In particular, the Survey specified a set of restrictions as follows: loss of sight, loss of hearing, speech difficulties, breathing difficulties, chronic pain or discomfort, loss of consciousness, learning difficulties, incomplete use of arms/legs, difficulty in gripping, emotional conditions, restriction in physical activities, disfigurement, mental illness, long-term effects of brain damage, receiving treatment for any other long-term conditions, or any other long-term conditions resulting in a restriction. The level of disability prevalence among children had not changed significantly since 1998 when the equivalent data were collected.

People who were identified as having a disability were asked about their need for assistance with core activities, that is, self-care, mobility and communication. A person was defined as having a profound disability if the person always needed assistance from another person to perform a core activity. A person was defined as having a severe disability if the person sometimes needed assistance from another person to perform a core activity, or had difficulty understanding or being understood by family or friends, or could communicate more easily using sign language or other non-spoken forms of communication.

A carer was defined as a person who provided any informal assistance to persons with disabilities or long-term conditions, or persons aged 60 years and older, as long as the assistance was ongoing or likely to be ongoing for at least six months. There were 472,500 primary carers aged 15 years or over, including carers of the elderly. In cases where the care recipient lived in the same household (which was true for most of the cases where children were recipients), the assistance was for one of the following activities: cognition or emotion, communication, health care, housework, meal preparation, mobility, paperwork, property maintenance, self-care and transport. A primary carer was the person who provided the most informal assistance to a person with a disability. The assistance had to be provided for one or more of the core activities (communication, mobility and self-care).

Appendix II

Maternal Employment and Characteristics in Australia (2004, 2006 and 2008)

\begin{tabular}{|c|c|c|c|c|}
\hline & \multicolumn{4}{|c|}{1 if mother works } \\
\hline & Probit (1) & Logit (2) & OLS (3) & FE (4) \\
\hline \multicolumn{5}{|l|}{ Mother's characteristics } \\
\hline Mother's age & $\begin{array}{l}0.076 * * * \\
(0.01)\end{array}$ & $\begin{array}{l}0.075 * * * \\
(0.01)\end{array}$ & $\begin{array}{l}0.075 * * * \\
(0.01)\end{array}$ & $\begin{array}{l}0.081 * * * \\
(0.02)\end{array}$ \\
\hline Mother's age squared & $\begin{array}{l}-0.001 * * * \\
(0.00)\end{array}$ & $\begin{array}{l}-0.001 * * * \\
(0.00)\end{array}$ & $\begin{array}{l}-0.001 * * * \\
(0.00)\end{array}$ & $\begin{array}{l}-0.001 * * * \\
(0.00)\end{array}$ \\
\hline $\begin{array}{l}1 \text { if mother was born outside } \\
\text { of Australia }\end{array}$ & $\begin{array}{l}-0.078 * * * \\
(0.02)\end{array}$ & $\begin{array}{l}-0.078 * * * \\
(0.02)\end{array}$ & $\begin{array}{l}-0.078 * * * \\
(0.02)\end{array}$ & \\
\hline 1 if mother does not speak & $-0.077 * * *$ & $-0.076 * * *$ & $-0.078 * * *$ & \\
\hline English at home & $(0.02)$ & $(0.02)$ & $(0.02)$ & \\
\hline 1 if mother is Aboriginal or & $-0.143 * * *$ & $-0.144 * * *$ & $-0.127 * * *$ & \\
\hline Torres Strait Islander & $(0.04)$ & $(0.04)$ & $(0.04)$ & \\
\hline 1 if mother completed Year 12 & $\begin{array}{l}0.097 * * * \\
(0.02)\end{array}$ & $\begin{array}{l}0.096 * * * \\
(0.02)\end{array}$ & $\begin{array}{l}0.096 * * * \\
(0.02)\end{array}$ & $\begin{array}{c}-0.153 \\
(0.16)\end{array}$ \\
\hline
\end{tabular}


Appendix II (Continued)

\begin{tabular}{|c|c|c|c|c|}
\hline & \multicolumn{4}{|c|}{1 if mother works } \\
\hline & Probit (1) & Logit (2) & OLS (3) & FE (4) \\
\hline 1 if mother did not complete & $0.113 * * *$ & $0.111 * * *$ & $0.113 * * *$ & $0.126 * *$ \\
\hline $\begin{array}{l}\text { Year } 12 \text { but has a trade/other } \\
\text { qualification }\end{array}$ & $(0.02)$ & $(0.02)$ & $(0.02)$ & $(0.06)$ \\
\hline 1 if mother completed Year 12 and & $0.163 * * *$ & $0.160 * * *$ & $0.165 * * *$ & 0.004 \\
\hline has a trade/other qualification & $(0.02)$ & $(0.02)$ & $(0.02)$ & $(0.15)$ \\
\hline 1 if mother completed a & $0.221 * * *$ & $0.219 * * *$ & $0.225 * * *$ & 0.005 \\
\hline Bachelor's Degree & $(0.02)$ & $(0.02)$ & $(0.02)$ & $(0.14)$ \\
\hline $\begin{array}{l}1 \text { if mother completed a } \\
\text { graduate diploma }\end{array}$ & $\begin{array}{l}0.208 * * * \\
(0.02)\end{array}$ & $\begin{array}{l}0.206 * * * \\
(0.02)\end{array}$ & $\begin{array}{l}0.212^{* * * *} \\
(0.02)\end{array}$ & $\begin{array}{c}-0.021 \\
(0.13)\end{array}$ \\
\hline \multicolumn{5}{|l|}{ or postgraduate degree } \\
\hline 1 if mother reports a long-term & $-0.042 * * *$ & $-0.042 * * *$ & $-0.042 * * *$ & $-0.027 *$ \\
\hline physical health problem & $(0.01)$ & $(0.01)$ & $(0.01)$ & $(0.02)$ \\
\hline 1 if mother reports a long-term & $-0.167 * * *$ & $-0.165 * * *$ & $-0.168 * * *$ & $-0.101 * * *$ \\
\hline mental health problem & $(0.03)$ & $(0.03)$ & $(0.03)$ & $(0.03)$ \\
\hline 1 if mother suffered a serious & -0.019 & -0.018 & -0.018 & -0.017 \\
\hline $\begin{array}{l}\text { illness, injury or assault in } \\
\text { the last year }\end{array}$ & $(0.02)$ & $(0.02)$ & $(0.02)$ & $(0.02)$ \\
\hline $\begin{array}{l}1 \text { if mother's relatives suffered } \\
\text { a serious illness, injury }\end{array}$ & -0.003 & -0.003 & -0.003 & -0.004 \\
\hline or assault in the last year & $(0.01)$ & $(0.01)$ & $(0.01)$ & $(0.01)$ \\
\hline 1 if the mother's parent, partner, & -0.009 & -0.009 & -0.009 & -0.010 \\
\hline $\begin{array}{l}\text { child, close family friend or } \\
\text { another relative died }\end{array}$ & $(0.01)$ & $(0.01)$ & $(0.01)$ & $(0.01)$ \\
\hline \multicolumn{5}{|l|}{ Household characteristics } \\
\hline 1 if partner is in household & $\begin{array}{l}0.091 * * * \\
(0.02)\end{array}$ & $\begin{array}{l}0.090 * * * \\
(0.02)\end{array}$ & $\begin{array}{l}0.087 * * * \\
(0.02)\end{array}$ & $\begin{array}{l}0.051 * \\
(0.03)\end{array}$ \\
\hline 1 if mother is married to & 0.024 & 0.024 & 0.027 & -0.014 \\
\hline the partner & $(0.02)$ & $(0.02)$ & $(0.02)$ & $(0.03)$ \\
\hline Number of siblings & $\begin{array}{l}-0.085 * * * \\
(0.01)\end{array}$ & $\begin{array}{l}-0.085 * * * \\
(0.01)\end{array}$ & $\begin{array}{l}-0.084 * * * \\
(0.01)\end{array}$ & $\begin{array}{l}-0.145^{* * *} * \\
(0.01)\end{array}$ \\
\hline Number of household members & 0.002 & 0.002 & 0.002 & -0.000 \\
\hline other than sibling or parent & $(0.01)$ & $(0.01)$ & $(0.01)$ & $(0.01)$ \\
\hline 1 if one of the siblings is a step-, & $0.058 * * *$ & $0.058 * * *$ & $0.056 * * *$ & $0.079 *$ \\
\hline half-, adopted or foster child & $(0.02)$ & $(0.02)$ & $(0.02)$ & $(0.05)$ \\
\hline \multirow[t]{2}{*}{1 if observed in 2006} & $0.062 * * *$ & $0.062 * * *$ & $0.063 * * *$ & 0.053 \\
\hline & $(0.01)$ & $(0.01)$ & $(0.01)$ & $(0.04)$ \\
\hline \multirow[t]{2}{*}{1 if observed in 2008} & $0.133^{* * *}$ & $0.133 * * *$ & $0.134 * * *$ & 0.104 \\
\hline & $(0.01)$ & $(0.01)$ & $(0.01)$ & $(0.07)$ \\
\hline $\begin{array}{l}\text { Number of observations } \\
\text { (mother } * \text { year) }\end{array}$ & 11,400 & 11,400 & 11,400 & 11,400 \\
\hline Chi-squared & 933.45 & 867.69 & & \\
\hline Log likelihood & -7035.22 & -7036.15 & -7397.65 & -1250.20 \\
\hline$F$-statistics & & & 68.16 & 21.06 \\
\hline
\end{tabular}

Notes: Robust standard errors in parentheses. *Significant at $10 \%$; **significant at $5 \%$; ***significant at $1 \%$. The regression results are for mothers of the LSAC B cohort (children aged 0-1 years in 2004). See Appendix III for more detailed definition of the sample. See Appendix III for the definition of the variables. All the included variables in Column 4 change over time. Mothers' health status and the incidence of health shocks change over time. Their marital status and the number of children (hence their composition) change as well. A small proportion of mothers shift from one education category to the other (for example, by attaining a qualification). Excluding the education dummies does not change the results.

Sources: The 2004, 2006, and 2008 Longitudinal Study of Australian Children. 
Appendix III

Data

Sample. In creating the analysis sample for the study of parental labour supply and children's health status, the following four types of households were excluded: (1) no female carer was present in the household $(0.4 \%)$; $(2)$ a female carer was not the parent of the Study Child (e.g., grandmother/aunt, $0.4 \%$ ); (3) the carer of the Study Child changed from a biological mother to step-mother (where it is difficult to justify the application of the fixed effects model, 0.06\%); and (4) necessary information (such as maternal employment, characteristics and major life events) was unavailable (7.6\%). This resulted in $4696 \mathrm{~B}$ cohort households and $4566 \mathrm{~K}$ cohort households (which are 94 per cent and 92 per cent of the original 2004 sample, respectively).

Parental employment. The LSAC asked mothers if they did any work in a job, business or farm in the week prior to the interview. It also asked whether mothers did any work without pay in a family business, and whether they had a job, business or a farm that they were away from in the week because of holidays, sickness or any other reasons (including casual, on-call or agency work). In this paper, mothers were defined to be employed (or to be working) if they answered 'yes' to one of these three questions, to include those who contributed to the family business (and hence towards household income) without pay and those who usually had a job but were temporarily away from it. The dummy variables for wage workers and self-employed workers take the value of one for those types of workers, and zero for all others.

Working mothers were also asked whether they worked for an employer or in their own business. Mothers who were working but not in their own business were also asked whether they were employed in a permanent/ongoing position or on some other basis, including a fixed-term contract or a casual basis. Three dummy variables indicating permanent, fixed-term and casual workers are defined based on this question. They take the value of zero for all other observations. All working mothers were asked how many hours per week they usually worked in all jobs, including any paid or unpaid overtime (without including travel time). If they worked irregular hours, the average number of hours worked over the last 4 weeks was taken. Mothers with working hours exceeding $34 \mathrm{~h}$ per week were defined to be 'full-time workers'.

Household income and carer allowance receipt. Parents were asked about the income they personally received, including wages/salary, profits/losses from their own businesses, shares in a partnership, rental property income, dividends/interest, government payments and child support from ex-partners. They were then asked how much they usually received from all sources in total, before income tax was deducted. Weekly income figures derived by the LSAC were used. Total household (parental) income was defined as the sum of weekly income reported by mothers, and their partners, if available. Parental income was used as a proxy for household income because only categorical information was available for household income (such as dummy variables indicating households whose income fell within a certain range) in the first wave. Some parents made a loss from identified income sources and these cases were recorded as cases with a loss. As the amount of the loss was unknown, for simplicity these cases were assumed to have had zero income. All of these figures were in terms of 2006 prices $(\$ 1000)$.

Information on the receipt of carer payment, which is a means-tested payment available to people whose caring responsibilities prevent them from undertaking substantial workforce participation, is only available in the 2008 LSAC. Therefore, it is not used in this analysis.

Parental Mental Health. Parental mental health is measured by the K6 Scale, which is based on six questions relating to the psychological conditions experienced during the past 4 weeks: how often the parent felt nervous, hopeless, restless/fidgety; felt that everything was an effort; felt so sad that nothing could cheer him/her up; felt worthless. Parents answered either 'all of the time', 'most of the time', 'some of the time', 'a little of the time' or 'none of the time' and were assigned the score of 4, $3,2,1$ or 0 , respectively, for each question. 
Children's current health status and long-term health problems. For children and mothers, a long-term physical/mental health problem was defined based on the following question: 'Does [the child/ mother] have any medical conditions or disabilities that have lasted, or are likely to last, for six months or more?' If the answer was 'Yes', the conditions were classified into a number of symptoms related to sight problems, hearing problems, speech problems, blackouts, learning difficulty, limited use of arms or fingers, difficulty in gripping, use of legs and feet, other physical condition, other disfigurement, difficulty in breathing, chronic pain, nervous condition, mental illness, head injury, other long-term condition and other condition requiring treatment. Those who indicated a nervous condition or a mental illness were classified to have a long-term mental health problem, while those who indicated the other conditions were classified as having a long-term physical health problem.

\section{Appendix IV}

Public programs for carers in Australia ${ }^{16}$

The main government payments directed to carers are the CP and the CA. CP started in 1983 originally as a spouse carer pension for men caring for their wives on Age/Invalid Pension for an extended period. It was extended to individuals caring for children with disability in 1998. To qualify, children must have profound disabilities or the carers have two or more children who need a level of care that is equivalent to the level required by having one child with a profound disability.

Launched in 1974, CA was initially called the handicapped child allowance. It was combined with the domiciliary nursing care benefit in 1999 and paid to carers of adults who required nursinghome level of care. To determine the eligibility among children aged 15 years or below, the Lists of Recognised Disabilities (LORD) and the Child Disability Assessment Tool (CDAT) have been used since 1998. It is first assessed whether a child has medical conditions listed on the LORD. If not, it is then assessed whether the child has the level of skills appropriate to age, such as language skills, self-care skills, social/community skills, and fine and gross motor skills. In cases of children aged 15 years or below, a carer who qualifies for CP because of the child's disability automatically receives $\mathrm{CA}$ for that child.

There have been a number of changes in the CA and CP criteria during the analysis period. First, the number of hours a carer can work, study or train increased from 20 to $25 \mathrm{~h}$ in 2005 . Second, in 2006, the criteria to qualify for CP were relaxed; that is, it was extended to children aged 6 to 16 years with severe intellectual, psychiatric and behavioural disabilities (see Appendix I for the definitions of profound and severe disabilities). As the K cohort was aged 6-7 years in 2006, only part of that cohort is likely to have been temporarily excluded from this extension of CP. For CA, some disabilities were added or changed on the LORD in 2004 and 2005. Also, in 2007, an annual supplemental payment of $\$ 1000$ was introduced for each child with a disability whose carer was receiving CA. Finally, since 2007, the carer adjustment payment scheme started which provides a one-off payment to families in exceptional circumstances who do not qualify for any income support payments. These changes suggest that mothers are surrounded by slightly different policy environments across years. However, as the changes applied to all the mothers, the year effects used in the panel analysis are likely to capture their effects on parental behaviours.

${ }^{16}$ This section is based on the Edwards et al. (2008). 